\begin{tabular}{|c|l|}
\hline Title & $\begin{array}{l}\text { Hydroclimate variability in the North China Plain and its link with El Niño-Southern Oscillation since 1784 A.D.: } \\
\text { Insights from tree ring cellulosed 180 }\end{array}$ \\
\hline Author(s) & Li, Qiang; Nakatsuka, Takeshi; Kawamura, Kimitaka; Liu, Yu; Song, Huiming \\
\hline Citation & $\begin{array}{l}\text { Journal of Geophysical Research, 116(D22), D22106 } \\
\text { https://doi.org/10.1029/2011D015987 }\end{array}$ \\
\hline Issue Date & 2011-11-19 \\
\hline Doc URL & http://hdl.handle.net/2115/49238 \\
\hline Rights & Copyright 2011 A merican Geophysical Union \\
\hline Type & article \\
\hline File Information & JGR116_D22106.pdf \\
\hline
\end{tabular}

Instructions for use 


\title{
Hydroclimate variability in the North China Plain and its link with El Niño-Southern Oscillation since 1784 A.D.: Insights from tree-ring cellulose $\delta^{18} \mathrm{O}$
}

\author{
Qiang Li, ${ }^{1,2}$ Takeshi Nakatsuka, ${ }^{2}$ Kimitaka Kawamura, ${ }^{3}$ Yu Liu, ${ }^{1,4}$ and Huiming Song ${ }^{1}$
}

Received 22 March 2011; revised 8 September 2011; accepted 10 September 2011; published 19 November 2011.

[1] We present here a chronology of tree-ring cellulose $\delta^{18} \mathrm{O}$ from 1784 to 2003 that is based on the individual measurements of five Larix principis-rupprechtii trees growing in the semiarid North China Plain (NCP; $\left.34^{\circ}-41^{\circ} \mathrm{N}, 107^{\circ}-120^{\circ} \mathrm{E}\right)$. This chronology has a significant, negative correlation with summer precipitation, relative humidity, and the Palmer Drought Severity Index. It is representative of regional summer hydroclimate variability in the NCP by analyzing its spatial correlation patterns with CRU TS3 precipitation grid data sets. Historically, extreme climate events (drought and flood) could be detected by the high-frequency (annual) signals in the chronology. The low-frequency (11 year moving average) signals are consistent with the time series of the drought frequency and the regional dryness-wetness index derived from historical documents in the NCP. Significant spatial correlation patterns of measured precipitation and the tree-ring cellulose $\delta^{18} \mathrm{O}$ chronology from the NCP with observed sea surface temperature in the eastern equatorial Pacific during the 1954-2003 and 1854-2003 periods suggest that the summer hydroclimate of the NCP has a close link with El Niño-Southern Oscillation. Mostly extreme dry or wet years identified by the chronology follow historical El Niño or La Niña events over the past 220 years, respectively.

Citation: Li, Q., T. Nakatsuka, K. Kawamura, Y. Liu, and H. Song (2011), Hydroclimate variability in the North China Plain and its link with El Niño-Southern Oscillation since 1784 A.D.: Insights from tree-ring cellulose $\delta^{18} \mathrm{O}, J$. Geophys. Res., 116 , D22106, doi:10.1029/2011JD015987.

\section{Introduction}

[2] Drought events have increased in intensity and frequency in response to global climate change during the last several decades, particularly in the heavily populated areas of monsoonal Asia [Dai et al., 2004]. Drought events have led to a number of environmental and ecological problems, such as destruction of wetlands, drying up of rivers, desertification and sinking ground [Piao et al., 2010]. Thus, hydroclimate variability has attracted increasing attention in monsoonal Asia [Qian and Zhu, 2001; Liu et al., 2003; Gou et al., 2007; Shen et al., 2007, 2008; Sano et al., 2009; Fang et al., 2009; Cook et al., 2010; Liu et al., 2009b, 2010]. For example, the North China Plain (NCP), where $26.8 \%$ of the national grain supply is cultivated, has become drier and warmer [Fu et al., 2009]. Since 1958, the annual precipitation of the NCP has

\footnotetext{
${ }^{1}$ State Key Laboratory of Loess and Quaternary Geology, Institute of Earth Environment, Chinese Academy of Sciences, Xi'an, China.

${ }^{2}$ Graduate School of Environmental Studies, Nagoya University, Nagoya, Japan.

${ }^{3}$ Institute of Low Temperature Science, Hokkaido University, Sapporo, Japan.

${ }^{4}$ Also at School of Human Settlements and Civil Engineering, Xi'an Jiaotong University, Xi'an, China.

Copyright 2011 by the American Geophysical Union. 0148-0227/11/2011JD015987
}

declined by approximately $43.9 \mathrm{~mm}$, and the annual mean temperature has increased by approximately $0.83^{\circ} \mathrm{C}[\mathrm{Fu}$ et al., 2009]. The NCP has been recognized as one of the most water-scarce regions in the world [Qian and Zhu, 2001; Feng and Hu, 2004; Fu et al., 2009]. Since 1972, interruption of river flow as a result of drought occurs almost every spring and summer season at the middle and lower reaches (mainly in the NCP) of the Yellow River, and this interruption results in water resource shortages, worsening of groundwater quality, wetland degradation, and biodiversity reduction, among other effects [Feng and $\mathrm{Hu}, 2004 ; \mathrm{Fu}$ et al., 2009]. Consequently, a historical understanding of hydroclimate variability will clarify the relative roles of natural variability and the anthropogenic impact on regional hydrology.

[3] El Niño-Southern Oscillation (ENSO) is widely recognized as one of the most important factors impacting global climate and weather patterns. El Niño (La Niña) results in a warming (cooling) over the east central tropical Pacific Ocean that decreases (increases) precipitation in western (eastern) Pacific regions [Allan et al., 1996]. On the NCP, many studies have focused on the influence of ENSO on summer precipitation using meteorologically observed data [Huang and Wu, 1989; Ding, 1994; Zhang et al., 1999; Gong and Wang, 1999; Wu, 2002; Wu et al., 2003; Feng and Hu, 2004; Zhou et al., 2009]. These studies found that when El Niño was in the development and maturation 


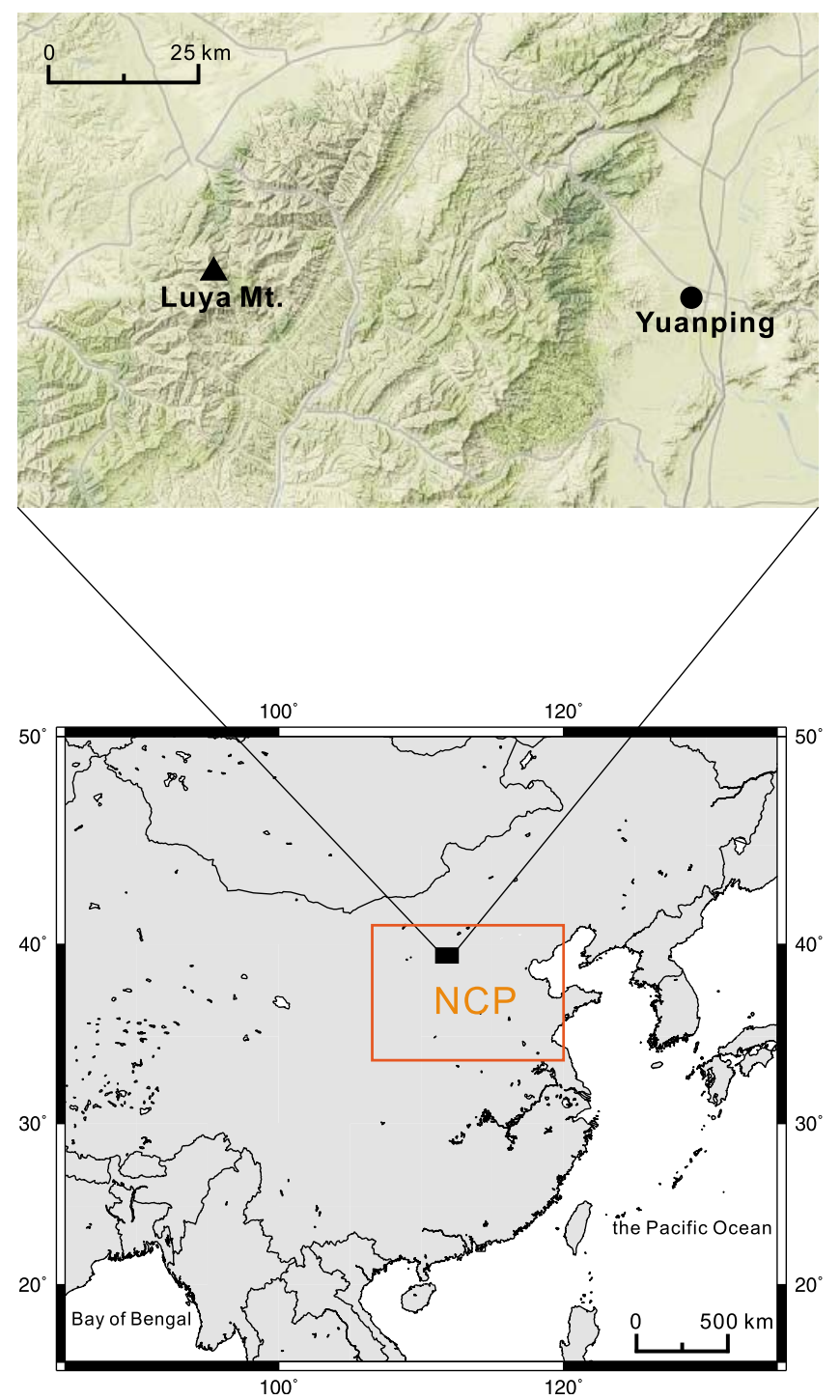

Figure 1. Map showing the sampling site (Luya Mountain; triangle) and the nearest meteorological station (Yuanping; circle) and the location of the North China Plain (NCP).

stage, the NCP often suffered from a shortage of summer precipitation. When an El Niño event faded or a La Niña event occurred, precipitation became abundant in the NCP. These results suggest that ENSO is closely connected with summer precipitation variability on the NCP. However, an understanding of the ENSO-NCP precipitation relationship is limited by some uncertainties, such as whether or not this relationship is stationary and how this relationship changes if it is nonstationary. These uncertainties are mainly caused by a scarcity of meteorological observations.

[4] To acquire knowledge that addresses above uncertainties, an understanding of how hydroclimate has varied in the past at the high-frequency domains is necessary. Natural proxies with yearly time resolutions, such as tree rings, corals, ice cores and stalagmites, can provide an essential means to evaluate climate in the preinstrumental observation era. Unfortunately, there have been few high (yearly)-resolution and long-period natural proxies on the NCP; because frequent human disturbances (e.g., wars and land use and cover changes) destroyed many natural proxies of the NCP over the past several centuries [Ge et al., 2008; Takata et al., 2009].

[5] In this paper, we present the first high-resolution hydroclimate chronology for the NCP based on $\delta^{18} \mathrm{O}$ of tree rings of Larix principis-rupprechtii. Our objective was to investigate (1) regional hydroclimate variability on the NCP from 1784 to 2003 and (2) the relationship between hydroclimatic variability with ENSO.

\section{Data, Materials, and Methods}

\subsection{The Sampling Site and Tree Ring Data}

[6] Trees were sampled from an alpine meadow on Luya Mountain $\left(38^{\circ} 44^{\prime} \mathrm{N}, 111^{\circ} 50^{\prime} \mathrm{E} ; 2400 \sim 2600 \mathrm{~m}\right.$ above sea level) in Shanxi Province, the NCP (Figure 1). This site lies in the environmentally sensitive zone. This is a transitional area between humid and arid conditions, forest and steppe. In the sampling site, the vegetation is sparse; the soil is shallow. The growing season for trees ranges from April to September in this region [Li et al., 2006]. According to the records of a nearby meteorological station in Yuanping $\left(38^{\circ} 45^{\prime} \mathrm{N}, 112^{\circ} 42^{\prime} \mathrm{E} ; 836 \mathrm{~m}\right.$ above sea level, records from 1954 to 2003 , about $75 \mathrm{~km}$ away from the sampling site), the mean annual precipitation was $428 \mathrm{~mm}$ during the observation period. The highest precipitation occurs in JulyAugust, which accounts for more than half of the total annual precipitation. The mean monthly relative humidity reaches a maximum in August (73.3\%). The temperature in the study area has exhibited a rapidly increasing trend, especially since the late 1970s. Inverse trends between temperature and precipitation $(r=-0.342, p<0.01)$ and between temperature and relative humidity $(r=-0.548, p<$ $0.0001)$ have been detected as well. In addition, relative humidity varies synchronously with precipitation $(r=0.708$, $p<0.0001$ ) [Li et al., 2011a].

[7] The dominant Larix principis-rupprechtii species were sampled at breast height using a $5 \mathrm{~mm}$ diameter increment borer in July 2004. To obtain the exact calendar year of per tree by cross dating, 29 trees were collected on Luya Mountain.

[8] It is general that growth rings are often missing in trees from arid or semiarid regions because of harsh hydrological conditions [Fritts, 1976; Liu et al., 2005; Cullen and Grierson, 2009]. Cross-dating was performed using the Skeleton Plot method [Stokes and Smiley, 1996]. The tree ring width was measured using a ring width measurement system by LINTAB with a precision of $0.01 \mathrm{~mm}$. Quality control of cross dating was carried out using the COFECHA program [Holmes, 1983]. The total length of the ring width chronology is 329 years, ranging from 1675 to 2003. The details of cross dating have been previously described by $Y i$ et al. [2006]. They suggested that the ring width chronology is positively correlated with local temperature in the sampling site, but cannot reconstruct temperature variability because of weak climate responses.

\subsection{Climate Data}

[9] To perform the response analysis between monthly climate parameters and tree-ring cellulose $\delta^{18} \mathrm{O}$, the available 
data, comprising precipitation amounts and maximum, minimum and mean temperatures, were collected from the Climatic Research Unit TS3 (CRU TS3, http://badc.nerc.ac.uk/ view/badc.nerc.ac.uk_ATOM_dataent_1256223773328276) database. Relative humidity $\overline{\text { data }}$ were extracted from the records of the Yuanping meteorological station because the CRU TS3 database does not contain relative humidity data for this region. The Palmer Drought Severity Index (PDSI) is a hydroclimate index that is more comprehensive than the temperature or precipitation data alone; the PDSI integrates antecedent monthly precipitation, temperature, moisture supply and moisture demand into a hydrological accounting system [Palmer, 1965; Dai et al., 2004]. Positive PDSI values indicate wetter conditions, and negative values indicate drier conditions. The PDSI is widely used to evaluate and monitor drought status in meteorology and hydrology in many regions, including in monsoonal Asia [Sano et al., 2009; Fang et al., 2009]. Dai et al. [2004] have derived monthly data sets of the PDSI values using meteorological records for global land areas on a $2.5^{\circ} \times 2.5^{\circ}$ grid (available at http:// www.cgd.ucar.edu/cas/catalog/climind/pdsi.html). The PDSI data set from a nearby grid point $\left(38^{\circ} 45^{\prime} \mathrm{N}, 111^{\circ} 15^{\prime} \mathrm{E}\right)$ of the sampling site was extracted for further analysis. We used the climate parameters described above for correlation analyses over the common period 1954-2003.

[10] In this study, the observed ENSO pattern is described as the NINO3 $\left(5^{\circ} \mathrm{S} \sim 5^{\circ} \mathrm{N}, 90^{\circ} \mathrm{W} \sim 150^{\circ} \mathrm{W}\right)$ Sea Surface Temperature Anomaly (SSTA) using the SST data from the NCDC SST version 3b data set (http://www.ncdc.noaa.gov/ oa/climate/research/sst/ersstv3.php).

\subsection{Measurement of Tree-Ring Cellulose $\delta^{18} O$}

[11] Among the 29 trees used for cross dating, there were very few samples suitable for isotope measurement. The tree ring samples usually contained extremely narrow rings $(\leq 0.1 \mathrm{~mm})$, which reoccurred continuously because of the harsh growing environment at the sampling site [ $\mathrm{Li}$ et al., 2006; Yi et al., 2006]. Exact separation of the extremely narrow rings was very difficult. To avoid error during the separation process of the annual rings, we only employed cross-dated samples that there are no missing rings and that these rings are not extremely narrow. The samples used were 36B (1688-1792), 17A (1675-1824), 08A (1784-2003) and $11 \mathrm{C}$ (1820-2003). In addition, 25C (1954-2003) has been measured by $\mathrm{Li}$ et al. [2011a], which can also be incorporated here. In total, above five tree ring cores were measured in this study. All of these tree ring cores reach the pith of the tree, except for 25C. Many rings have indistinct boundaries between earlywood and latewood. Therefore, we used whole annual rings, including earlywood and latewood, for the isotopic analyses.

[12] The annual ring was cut carefully with a razor blade under a binocular microscope. The excised segment of the annual ring was then mounted on the top of a small aluminum cylinder using synthetic glue that could be easily removed by organic solvent (acetone) during the following cellulose extraction process [Nakatsuka et al., 2004]. Once fixed, each ring was sliced into $20 \mu \mathrm{m}$ thin sections along the fibrous direction using a rotary microtome to allow chemical reagents to be more easily absorbed into the wood tissues. Type $\alpha$-cellulose was extracted from thin, mixed sections of the same ring using a modified Jayme-Wise method [Loader et al., 1997].

[13] We loaded $0.13 \sim 0.17 \mathrm{mg}$ of homogeneous $\alpha$-cellulose into a silver capsule in duplicate for each sample, and then the oxygen isotope ratios of the cellulose were determined using a continuous flow system with a pyrolysis-type elemental analyzer (ThermoQuest TCEA) and an isotope ratio mass spectrometer (ThermoQuest Delta plus XL) [Sharp et al., 2001; Nakatsuka et al., 2004]. The oxygen isotope ratios are expressed in the $\delta$ as per mil (\%o) with respect to the international stable oxygen isotope standard the Vienna Standard Mean Ocean Water (VSMOW): $\delta^{18} \mathrm{O}=$ $\left[\left(R_{\text {sample }} / R_{\text {standard }}\right)-1\right] \times 1000 \%$, where $R_{\text {sample }}$ and $R_{\text {standard }}$ are ${ }^{18} \mathrm{O} /{ }^{16} \mathrm{O}$ ratios in sample and standard, respectively [Coplen, 1996]. The Merck cellulose $\left(\delta^{18} \mathrm{O}=27.4 \pm 0.3 \%\right.$, VSMOW; Merck KGaA, Darmstadt, Germany) is employed as the laboratory working standard to calibrate sample oxygen isotope values. The mean value of the tree-ring cellulose oxygen isotope ratios was obtained from duplicate analyses on an annual cellulose sample. The analytical uncertainty was less than $0.2 \%$ o $(1 \sigma)$ in repeated measurements of the Merck cellulose.

\section{Results}

[14] The time series for the tree-ring cellulose $\delta^{18} \mathrm{O}$ obtained for the five cores in this study are presented in Figure 2a. All of the tree-ring cellulose $\delta^{18} \mathrm{O}$ series show highly consistent variations in the overlapping periods (Table 1).

[15] The main tree-ring $\delta^{18} \mathrm{O}$ chronology comprises four time series of tree-ring cellulose $\delta^{18} \mathrm{O}(17 \mathrm{~A}, 08 \mathrm{~A}, 11 \mathrm{C}$, and $25 \mathrm{C})$. Owing to instability in the signal strength before 1783 A.D. and unclear reason of decreasing $\delta^{18} \mathrm{O}$ on $36 \mathrm{~B}$ (see section 4.1), the period of effective tree-ring cellulose $\delta^{18} \mathrm{O}$ chronology will adopt duration of 1784-2003 for further analysis. The tree-ring cellulose $\delta^{18} \mathrm{O}$ values encompass a wide range, extending from $20.1 \%$ to $29.5 \%$, with a mean value and a standard deviation of $24.7 \%$ and $1.79 \%$ during the period 1784-2003, respectively.

\section{Discussion}

\subsection{The Length of Main Chronology}

[16] To capture a representative site isotope signals, the minimum number of trees for tree ring isotopes studies is generally far few than that of ring width or density studies [McCarroll and Loader, 2004; Leavitt, 2010]. In some cases, two trees could even represent the common regional signal for tree ring isotopes studies [Leavitt and Long, 1984; Robertson et al., 1997; McCarroll and Pawellek, 1998; Leavitt, 2010; Li et al., 2011a]. Leavitt [2010] suggested that the minimum number of trees should be calculated by the Expressed Population Signal (EPS) [Wigley et al., 1984]. In this study, the EPS is calculated by different overlapping periods of the tree-ring cellulose $\delta^{18} \mathrm{O}$ series. They are 0.96 for period of 1954-2003 $(n=3), 0.95$ for period of 1820 $1953(n=2), 0.93$ for period of $1793-1819(n=2), 0.99$ for period of $1784-1792(n=3)$ and 0.80 for period of 1688 $1783(n=2)$. The EPSs of the first three periods are higher than the guide threshold value of 0.85 , above which one can 


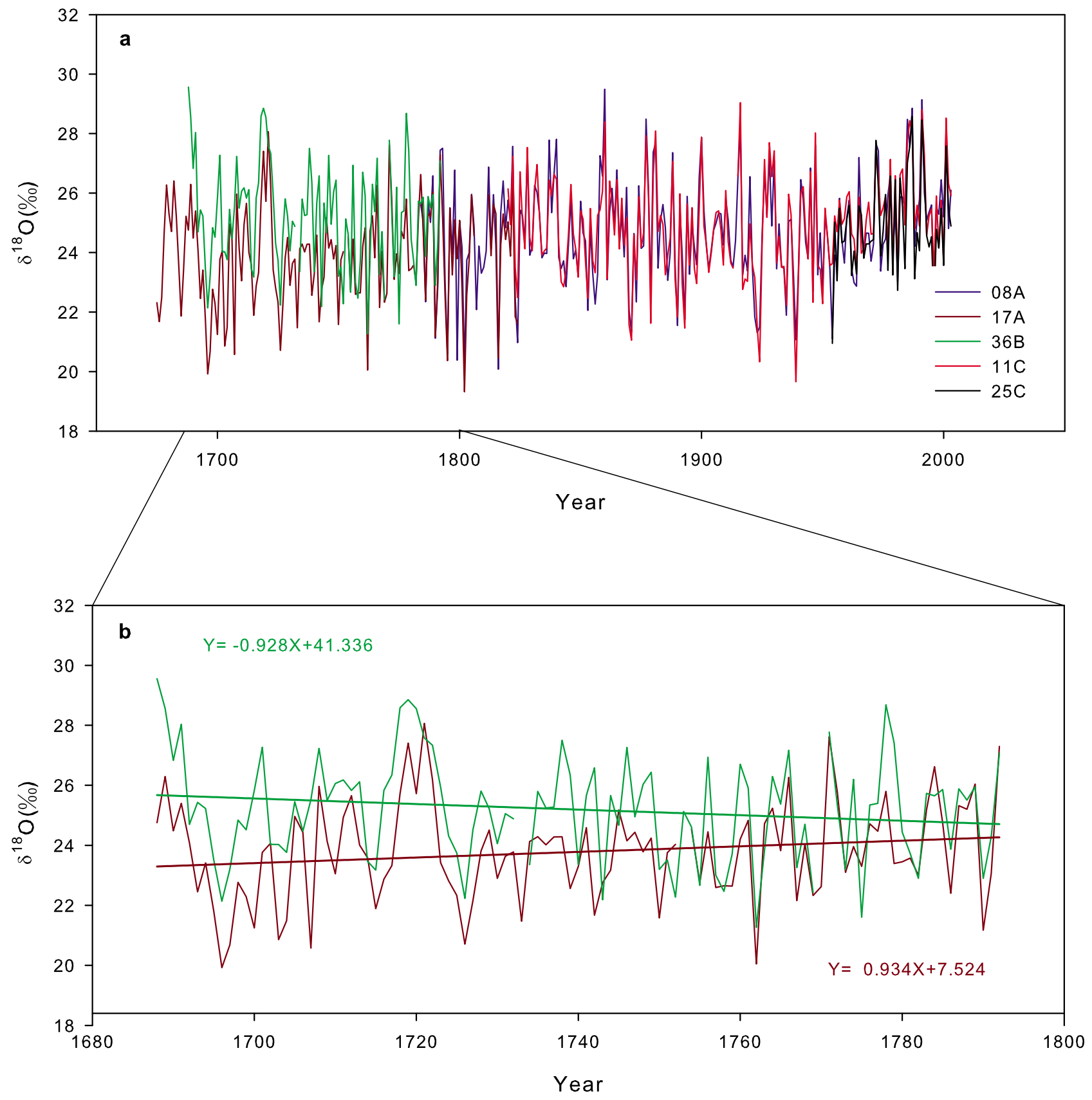

Figure 2. (a) Tree-ring cellulose $\delta^{18} \mathrm{O}$ series of five samples. (b) Least squares linear fits to the cellulose $\delta^{18} \mathrm{O}$ time series of $36 \mathrm{~B}$ and $17 \mathrm{~A}$ and fitted functions over the common period of 1688-1792.

infer that the averaged time series represents the common regional signal. However, there is a strong decline of the EPS in period of $1688-1783$, indicating instability in the signal strength before 1783 A.D.
[17] Trends in the tree-ring cellulose $\delta^{18} \mathrm{O}$ are somewhat different between $36 \mathrm{~B}$ and $17 \mathrm{~A}$, although correlation between the two time series is significantly high (Table 1). Equations derived from least squares linear plots are shown

Table 1. Correlation Coefficients Between Individual Tree-Ring Cellulose $\delta^{18}$ O Series ${ }^{\mathrm{a}}$

\begin{tabular}{|c|c|c|c|c|c|}
\hline Sample Number & $36 \mathrm{~B}$ & $17 \mathrm{~A}$ & $08 \mathrm{~A}$ & $11 \mathrm{C}$ & $25 \mathrm{C}$ \\
\hline $36 \mathrm{~B}$ & 1 & & & & \\
\hline $17 \mathrm{~A}$ & $0.67(1688-1792)$ & 1 & & & \\
\hline 08A & $0.98(1784-1792)$ & $0.90(1784-1824)$ & 1 & & \\
\hline $11 \mathrm{C}$ & - & - & $0.90(1820-2003)$ & 1 & \\
\hline $25 \mathrm{C}$ & - & - & $0.86(1954-2003)$ & $0.92(1954-2003)$ & 1 \\
\hline
\end{tabular}

${ }^{\mathrm{a}}$ Years in parentheses show the overlapping period between two series. All $p<0.01$. 


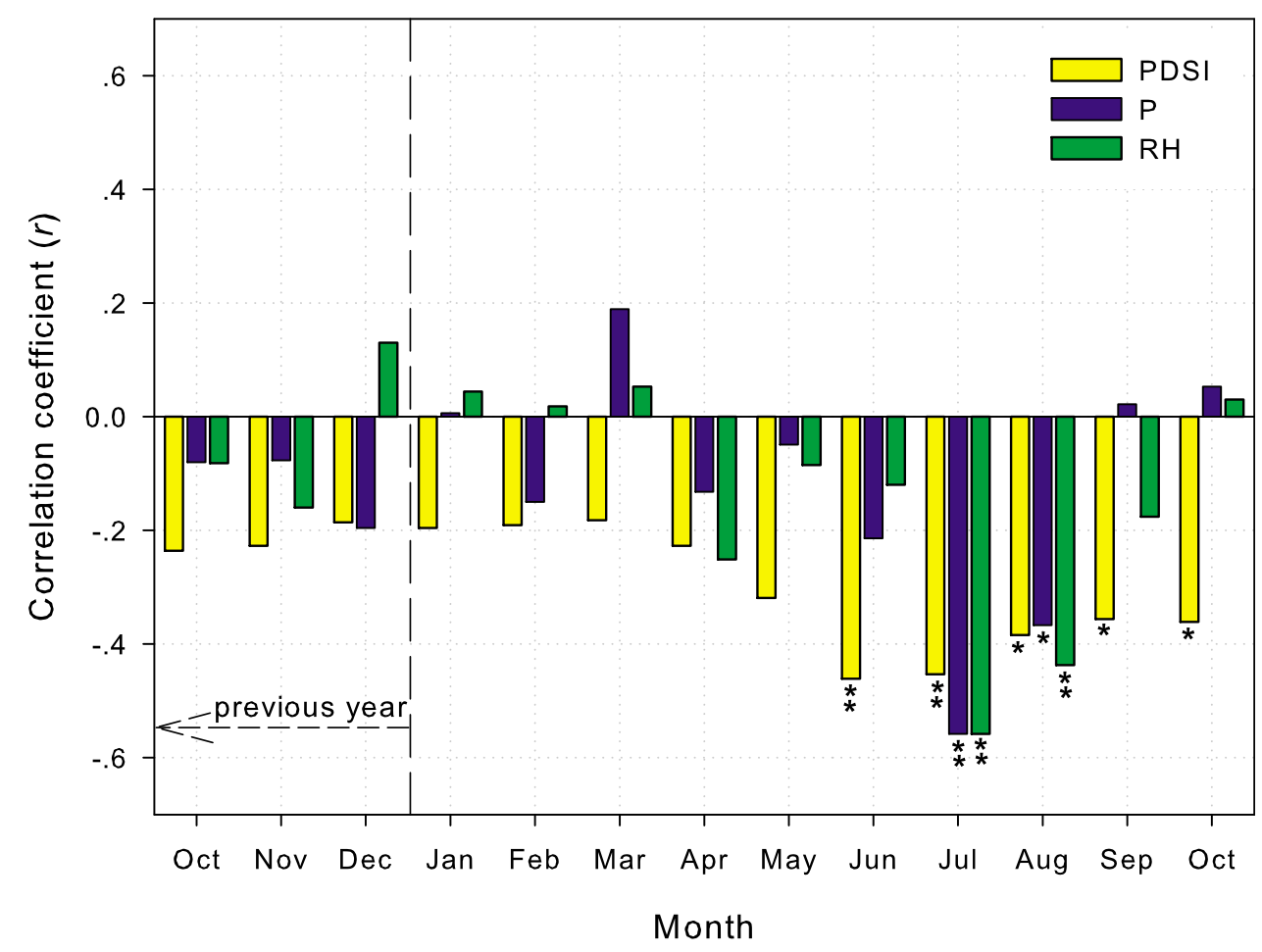

Figure 3. Response of the tree-ring cellulose $\delta^{18} \mathrm{O}$ to monthly Palmer Drought Severity Index, precipitation (P), and relative humidity (RH) from the previous to current October during 1954-2003. A single asterisk and double asterisks indicate significance levels of $95 \%$ and $99 \%$, respectively.

in Figure $2 \mathrm{~b}$ for the tree-ring cellulose $\delta^{18} \mathrm{O}$ series for $36 \mathrm{~B}$ and $17 \mathrm{~A}$ over the common period of $1688-1792$. The results reveal a long-term decreasing trend in the $\delta^{18} \mathrm{O}$ value for $36 \mathrm{~B}$, although there is not an obvious long-term decreasing trend in the $\delta^{18} \mathrm{O}$ values for 17A. Treydte et al. [2006] suggested that the Juvenile effect (age-related decline trend in juvenile trees) of the tree-ring cellulose $\delta^{18} \mathrm{O}$ could exist in young juniper trees in northern Pakistan. Nakatsuka et al. [2008] also reported that the Juvenile effect may influence the decreasing and increasing trends in the tree-ring cellulose $\delta^{18} \mathrm{O}$ and $\delta \mathrm{D}$, respectively, during the young periods of larch trees in Kamchatka Peninsula, Russia. Conversely, the Juvenile effect was not observed in oak cellulose $\delta^{18} \mathrm{O}$ from western France, whereas the cellulose $\delta^{13} \mathrm{C}$ and width presented obvious Juvenile effects [Raffalli-Delerce et al., 2004; Masson-Delmotte et al., 2005]. Leavitt et al. [2010] suggested that the Juvenile effect was more obvious in stable carbon and hydrogen isotopes, comparing with stable oxygen isotope in tree rings. The physiological mechanism of the Juvenile effect of the tree-ring cellulose $\delta^{18} \mathrm{O}$ is still unclear by now, and this effect may correlate with tree species, stand environments, and others. However, there are no other evidences to prove the Juvenile effect of $36 \mathrm{~B}$ and to interpret the difference between 36B and 17A in this study. More studies concerning the isotopic Juvenile effect are necessary and should include more tree species and more detailed measurements of individual tree ecophysiological conditions.

[18] As discussed above, we remove the portion of the tree-ring cellulose $\delta^{18} \mathrm{O}$ chronology from 1675 to 1783 . The remaining portion of the chronology, during 1784-2003, will be as the main chronology for further analysis.

\subsection{Climatic Response and Spatial Representation}

[19] Coefficients of Pearson's correlation are computed between interannual variations in the tree-ring cellulose $\delta^{18} \mathrm{O}$ and the monthly mean climatic parameters from the previous October to the current October during the last 50 years. Overall, the tree-ring cellulose $\delta^{18} \mathrm{O}$ is negatively correlated with PDSI, precipitation and relative humidity for the growing season in the current year (Figure 3 ).

[20] There are no significant correlations of $\delta^{18} \mathrm{O}$ values with temperature or climate parameters from previous fall to current early spring (Figure 3), although we measured cellulose $\delta^{18} \mathrm{O}$ from whole ring, including earlywood and latewood. This could be explained as follows. The extremely narrow latewood suggests that earlywood does not only reflect spring growth and but also record the climate signals in summer season because "early" and "late" wood are just morphological definitions in wood anatomy and they do not necessarily correspond to the "spring" and "summer" (or "autumn") growth phases. Additionally, Larix principisrupprechtii belongs to the species of shallow root system that does not access groundwater [Sakai et al., 2007; Li et al., 2011a].

[21] In particular, there are strong correlations in summer months, indicating that the hydroclimate during the summer is the primary, controlling factor for tree-ring cellulose $\delta^{18} \mathrm{O}$ in this region. By integrating multiple months, the highest correlation coefficient appears at July-August relative humidity $(r=-0.561, p<0.001)$, June-July-August precipitation $(r=-0.552, p<0.001)$ and June-July PDSI $(r=$ $-0.467, p<0.001)$. However, the tree-ring cellulose $\delta^{18} \mathrm{O}$ can only explain $32 \%, 31 \%$ and $22 \%$ of the variances in the 
actual relative humidity, precipitation and the PDSI during the common period 1954-2003. We attribute this result, at least in part, to the necessity of using climatic data that is based on records from sparse meteorological stations of the NCP (e.g., about $75 \mathrm{~km}$ away from the sampling site in this study). Sparse meteorological stations have previously influenced verification of climate signals in tree rings in Asia [Sano et al., 2009; Cook et al., 2010]. In addition, precipitation $\delta^{18} \mathrm{O}$ is an important factor controlling tree-ring cellulose $\delta^{18} \mathrm{O}$ values [Roden et al., 2000]. The relationship between precipitation $\delta^{18} \mathrm{O}$ and precipitation and temperature is poor in the sampling site [Li et al., 2011a], which may also results in low explained variances of the tree-ring cellulose $\delta^{18} \mathrm{O}$ to actual relative humidity, precipitation and the PDSI.

[22] The physiological mechanism of tree-ring cellulose $\delta^{18} \mathrm{O}$ suggests that the oxygen isotope ratios of tree rings are primarily determined by relative humidity and the oxygen isotope ratios of precipitation [Dongmann et al., 1974; Roden et al., 2000; McCarroll and Loader, 2004; Nakatsuka et al., 2004, 2008; Farquhar and Cernusak, 2005; Treydte et al., 2006; Saurer et al., 1997, 2008; Li et al., 2011b; Tene et al., 2011]. In the sampling site, relative humidity becomes more important because the $\delta^{18} \mathrm{O}$ of precipitation is not simply correlated with a single climate parameter, such as temperature or precipitation, in this region [ $\mathrm{Li}$ et al., 2011a]. Conversely, relative humidity has a clear mechanistic, negative linear correlation with $\delta^{18} \mathrm{O}$ of leaf water based on the leaf-water enrichment model [Craig and Gordon, 1965; Roden et al., 2000].

[23] In this study, the tree-ring cellulose $\delta^{18} \mathrm{O}$ chronology can be considered to represent the hydroclimate variability of the NCP not only because of its significant statistical correlation with hydroclimate parameters, but also because of its physiological mechanical. Both the statistical correlation and the mechanical model [Roden et al., 2000] indicate that high and low cellulose $\delta^{18} \mathrm{O}$ values are due to dry and wet conditions, respectively.

[24] To understand how the large-scale hydroclimate could be represented by the tree-ring cellulose $\delta^{18} \mathrm{O}$ chronology, spatial correlation analysis was carried out between the treering cellulose $\delta^{18} \mathrm{O}$ and the summer (June-August) CRU TS3 precipitation gridded data sets (http://badc.nerc.ac.uk/view/ badc.nerc.ac.uk ATOM dataent 1256223773328276). The time scale of the CRU TS3 data is 106 years (1901-2006); however, most meteorological stations in China were established starting in the 1950s. The 1901-1950s CRU TS3 gridded data were obtained by interpolating calculations from several very sparse meteorological stations, including Beijing $\left(39^{\circ} \mathrm{N}, 116^{\circ} \mathrm{E}\right)$, Tianjin $\left(39^{\circ} \mathrm{N}, 117^{\circ} \mathrm{E}\right)$ and Qingdao $\left(36^{\circ} \mathrm{N}\right.$, $120^{\circ} \mathrm{E}$ ), which have records dating to 1901 . Thus, spatial correlations were investigated in two periods, 1954-2003 and 1901-2003, to avoid possible influences of different data densities. The results indicate that the correlation is significant in both periods (see Figure 4). The area of significant correlation covers most regions of the NCP. Therefore, we conclude that the tree-ring cellulose $\delta^{18} \mathrm{O}$ chronology is representative of the regional hydroclimate variability of the NCP.

\subsection{Extreme Events (High-Frequency Signals)}

[25] Anomalous precipitation events that include drought and flood (extreme events) are the most frequent natural disasters in monsoonal Asia [Qian and Zhu, 2001; Shen et al.,
2008]. The tree-ring cellulose $\delta^{18} \mathrm{O}$ chronology, which possesses high resolution and absolute dating, has the potential to detect drought and flood events before the period of the meteorological observation. In the NCP, historical documents are particularly abundant because the NCP has been the traditional center of Chinese politics, economics and culture since 1421 in the Ming Dynasty [Zhang, 1988a]. Historically severe drought and flood events have been derived from the anciently governmental archives and local gazettes for the past several centuries [Zhang, 1988b, 2003; Zhang et al., 2003; Chen, 2007; Shen et al., 2007; State Office of State Flood Control and Drought Relief Headquarters, 2007; Zeng et al., 2009]. From 1784 (the beginning of our chronology) to 1954 (the start of instrumental observation), there are eight severe drought events and six severe flood events with single or continuous years reported in the historical documents. The severe droughts occurred in 1792, 1813, $1835,1858,1876-1878,1899-1900,1920-1921$, and 19261930. The drought during 1876-1878 was one of the most severe drought events recorded in the historical documents since 1784 A.D., influencing most of the East Asia region [Cook et al., 2010]. In 1877, there was no precipitation for more than 200 days on the NCP [Shen et al., 2007, 2008; Zeng et al., 2009]. The 1876-1878 drought induced severe crop failure, which bereaved population lives of more than 13 million in the NCP [Chen, 2007; Zeng et al., 2009]. The cellulose $\delta^{18} \mathrm{O}$ value in 1877 was $28.5 \%$, which is $3.8 \%$ o higher than the average cellulose $\delta^{18} \mathrm{O}$ value $(24.7 \%$ ). The 1920s droughts, including the 1920-1921 drought and the 1926-1930 drought, affected many regions, which has been verified by many studies in northwest China [Liang et al., 2006], central China [Cai et al., 2008] and northeast China [Liu et al., 2009b, 2010]. High cellulose $\delta^{18} \mathrm{O}$ values of $26.6 \%$ and $26.3 \%$ (averaged values) were found for 1920 and 1926-1930, respectively. In particular, Shen et al. [2007] detected extreme drought events in 1835, 1877, 1900, and $1928-1929$ in larger regions of eastern China $\left(22^{\circ}-40^{\circ} \mathrm{N}\right.$, $105^{\circ}-122^{\circ} \mathrm{E}$ ) using the historical documents, and these events could be found in the tree-ring cellulose $\delta^{18} \mathrm{O}$ chronology as well. Overall, the eight severe drought events in the historical documents correspond to eight high $\delta^{18} \mathrm{O}$ values in the treering cellulose $\delta^{18} \mathrm{O}$ chronology (Figure $5 \mathrm{a}$ ). On the other hand, severe flood events occurred in 1802, 1823-1824, 1892, 1922, 1939, and 1954 in the historical documents. All of the severe flood events occur at years with extremely low values in the tree-ring cellulose $\delta^{18} \mathrm{O}$ chronology (Figure 5a).

[26] However, some other extremely high and low cellulose $\delta^{18} \mathrm{O}$ values exist in the chronology that do not correspond to drought and flood events in the historical documents, respectively. For example, extremely low and high cellulose $\delta^{18} \mathrm{O}$ values appear in $1816(20.8 \%$ ) and $1860(29.5 \%$ ), and no records of flood or drought events can be found for these 2 years in the historical documents. We consider that our samples were collected at a mountain region, where the precipitation may a little bit be different with the regional precipitation, while the historical documents only based on records of regional climate.

\subsection{Long-Term Hydroclimate Variability (Low-Frequency Signals)}

[27] To investigate the variability of a time series, cumulative departure is an intuitively way to express long-term 

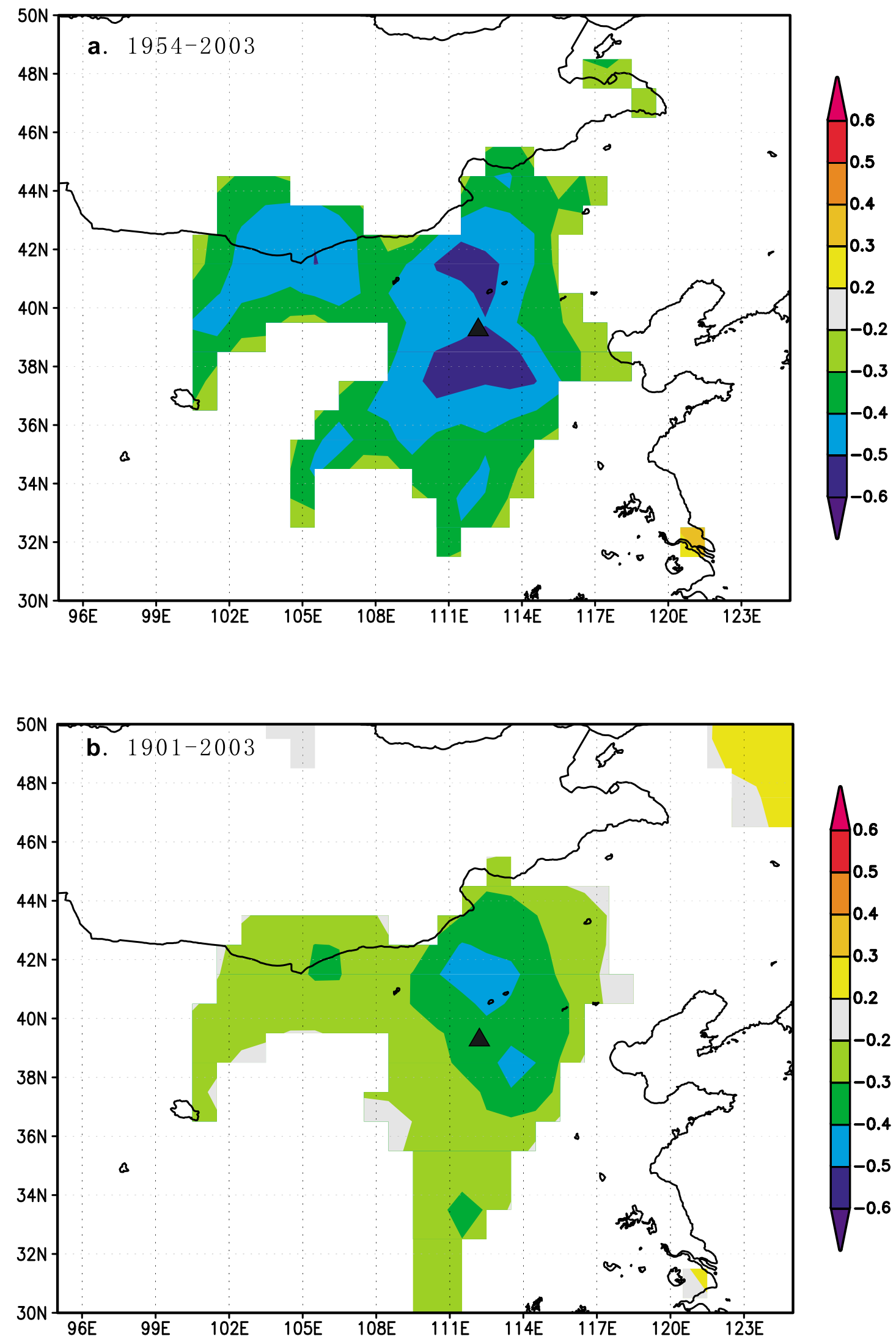

Figure 4. Spatial correlation patterns between the tree-ring cellulose $\delta^{18} \mathrm{O}$ and summer (June-August) CRU TS3 precipitation grid data sets during (a) 1954-2003 and (b) 1901-2003. The triangle shows the sampling site. 

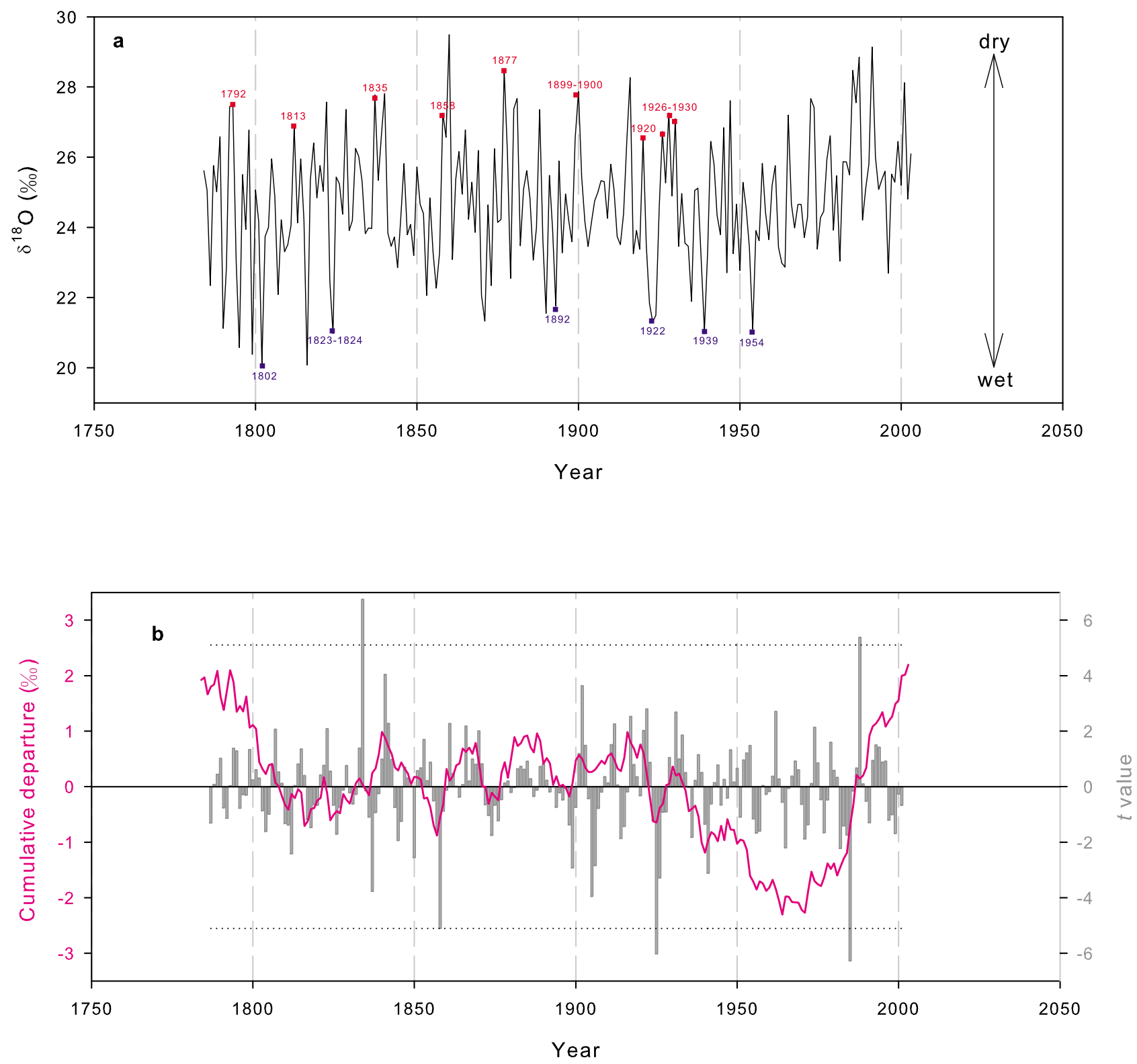

Figure 5. (a) Interannual variation of the tree-ring cellulose $\delta^{18} \mathrm{O}$ with severe drought events (red) and flood events (blue) years in the historical documents and (b) results of cumulative departure (curve) and sliding $t$ test (bar) with $\alpha=0.01$ confidence level (dashed lines).

trend: the long-term upward or downward movement of the cumulative departure curve represents increased or decreased trend [Tilahun, 2006; Wang et al., 2007]. In addition, we employ sliding $t$ test method [Fu and Wang, 1992] to detect mutation years of the hydroclimate variability. In Figure 5b, the result of sliding $t$ test shows there are 4 mutation years (1834, 1925, 1985, and 1987) at $\alpha=0.01$ confidence level. Incorporating the result of the cumulative departure, Figure $5 \mathrm{~b}$ reveals that 1784-1834 was a wetter period; long-term stable hydroclimate occurred in period of 1834-1925; it became wetter during 1925-1970s, which is consistent with averaged precipitation records during 1900-1950 on the NCP by Qian and Zhu [2001]; and the long-term drying mainly occurred during the period of the 1970s-2000s, which may be attributed to rapid global warming in the most recent several decades [Cai et al., 2008; Liu et al., 2009a].
[28] We compared the decadal frequency of droughts, which was derived from historical documents by Shen et al. [2008], with the tree-ring cellulose $\delta^{18} \mathrm{O}$ chronology. The decadal drought frequency is high in the 1850 s (four times per decade), the 1870s (four times per decade) and the 1990s (five times per decade), as shown in Figure 6a. These droughts correspond with two peaks in the 11 year moving average time series of the tree-ring cellulose $\delta^{18} \mathrm{O}$ in Figure 6a. Using a three-point moving average, the decadal drought frequency also reveals a drying trend for the whole period of 1784 2003. Although the droughts in the mid-19th century are extreme cases, they do not exceed the severity of the current droughts. This situation is the same as the results from the tree-ring cellulose $\delta^{18} \mathrm{O}$.

[29] In the NCP, the dryness-wetness index (DWI) is the only available long proxy of the paleoclimate, which is a 

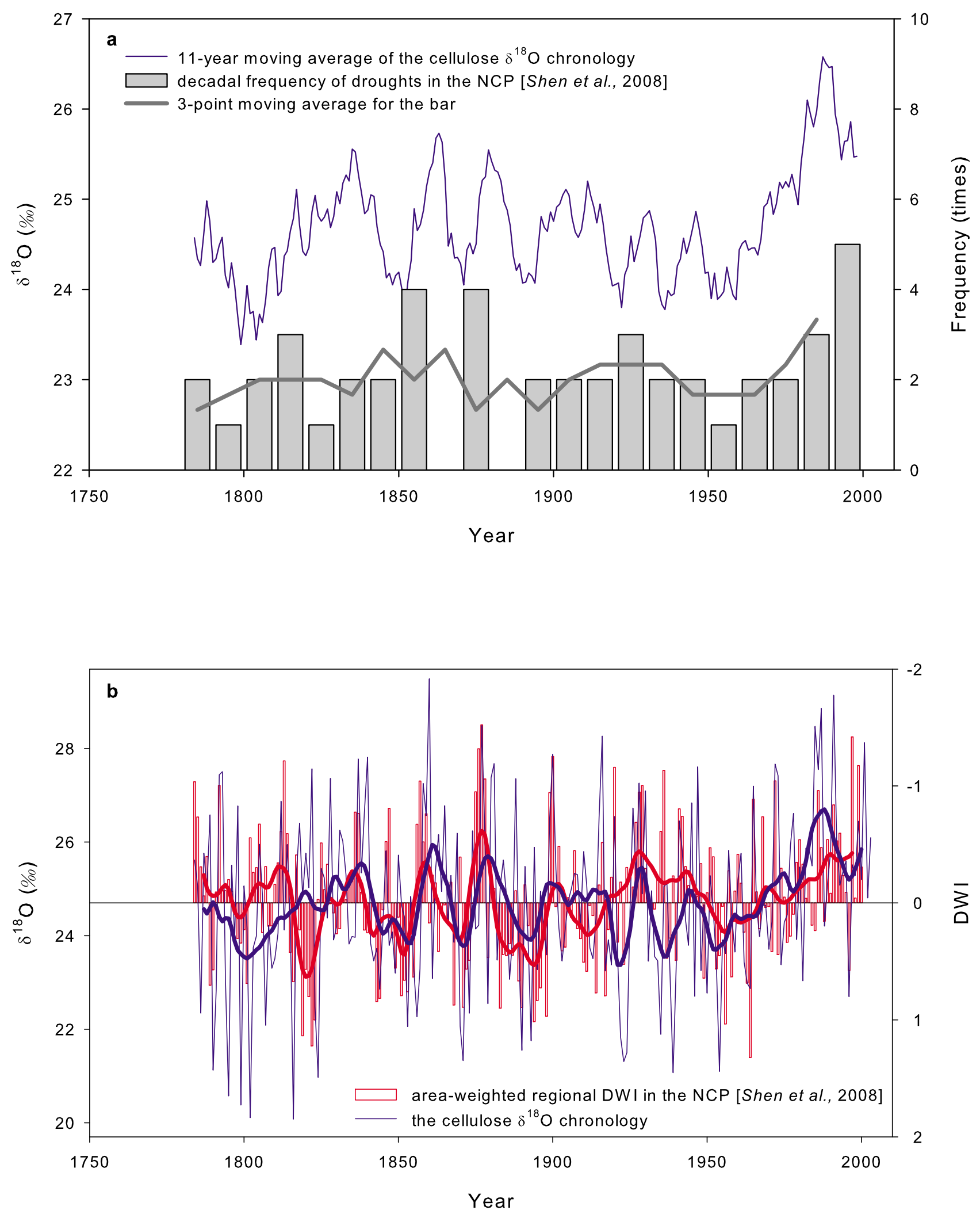

Figure 6. (a) Comparison between the tree-ring cellulose $\delta^{18} \mathrm{O}$ chronology and decadal frequency of drought events on the NCP and (b) area-weighted regional dryness-wetness index (DWI) of the NCP. Bold lines are 10 year low-pass filtered data. 
a. Actual precipitation with NCDC SST (1954-2003)

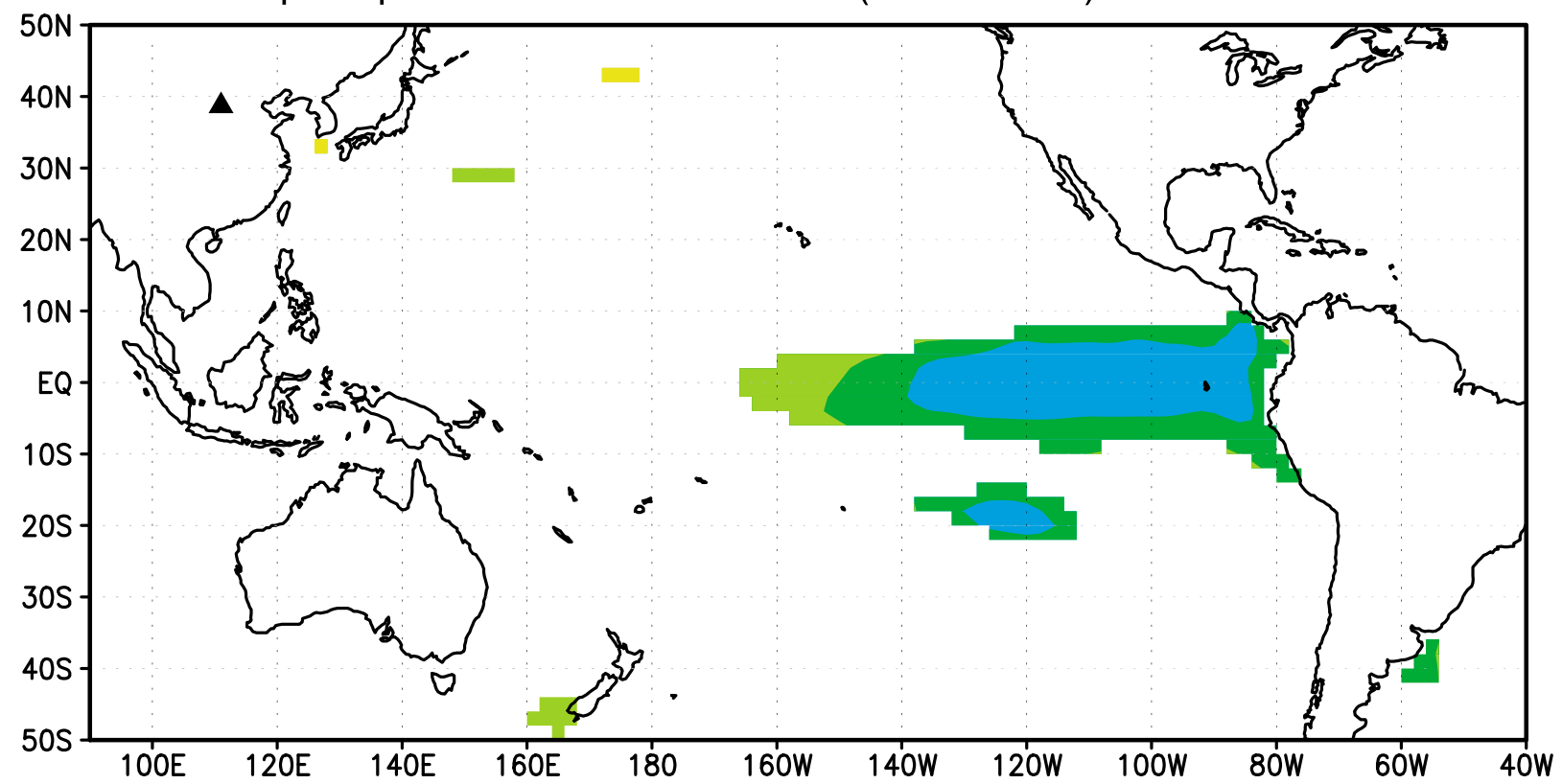

b. The tree-ring cellulose $\delta^{18} \mathrm{O}$ with NCDC SST (1854-2003)

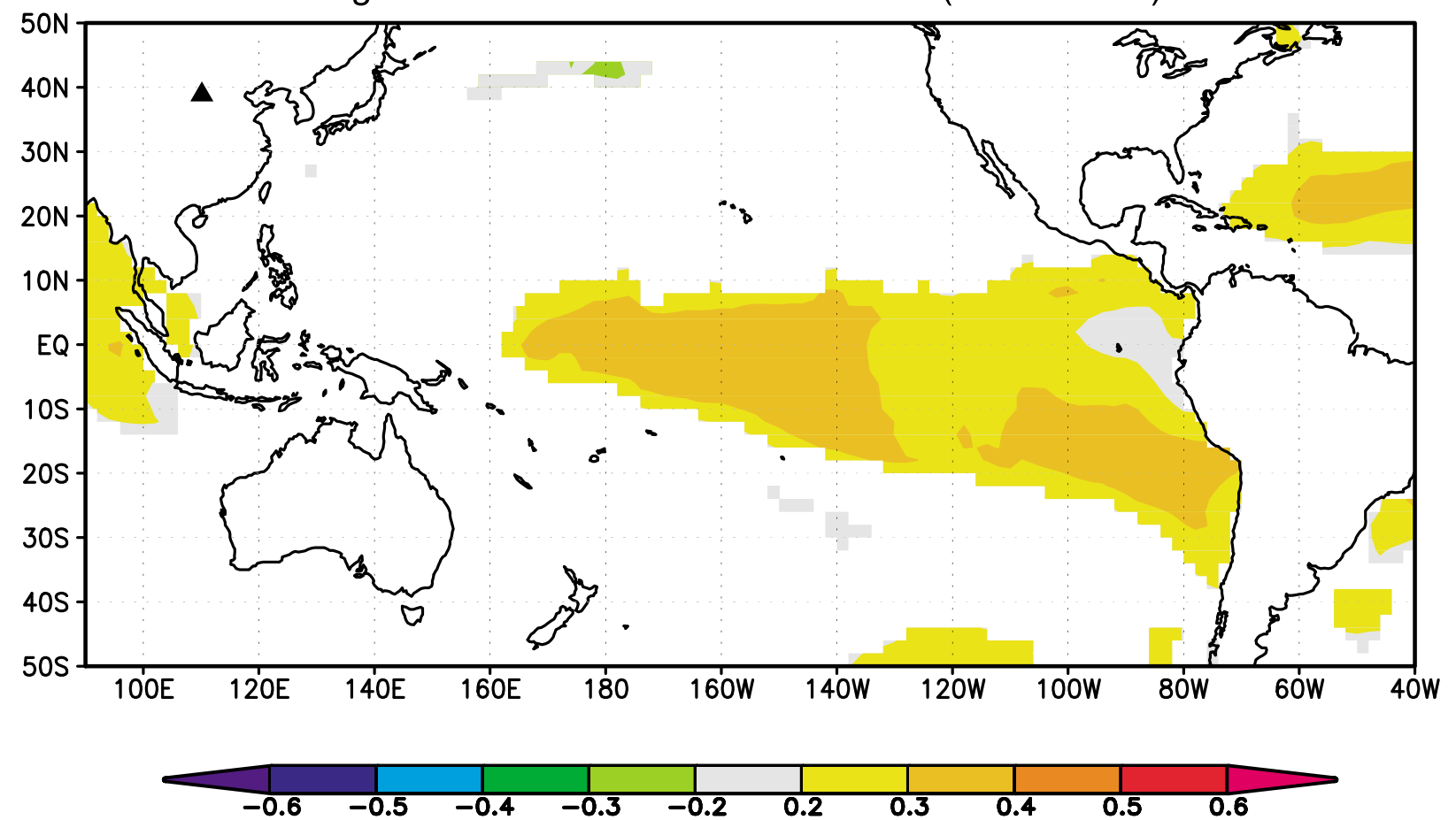

Figure 7. Spatial correlation patterns between NCDC SST v3b and (a) actual summer precipitation and (b) the tree-ring cellulose $\delta^{18} \mathrm{O}$ over their overlapping periods. The triangle shows the meteorological station or sampling site.

well-dated and annual-resolution series. The DWI is derived from many historical documents and published by the Chinese National Meteorological Administration [1981]. The DWI is defined as a dry and wet grade index of rainfall in the main rainy season [Zhang, 1988a], which was extended to 2000 by Zhang et al. [2003]. The DWI only has five grades, which are -2 (very dry), -1 (dry), 0 (normal),
1 (wet), and 2 (very wet). There are 120 stations for collecting the DWI data set in the entirety of China. Spatial distribution of the DWI is uneven. Shen et al. [2008] developed an area-weighted, average regional DWI of the NCP based on a database of spatial coverage for these sites using the geographic information system (GIS) technique, which is an excellent regional representation of the entire 
Table 2. Extremely Dry Years Detected by the Tree-Ring Cellulose $\delta^{18} \mathrm{O}$ Chronology With Classified El Niño Events From Quinn and Neal [1992] and Observed ENSO Events ${ }^{\mathrm{a}}$

\begin{tabular}{cc}
\hline Extremely Dry Years & El Niño Events (Classify) \\
\hline 1789 & - \\
1792 & $1791(\mathrm{VS})$ \\
1793 & $1791(\mathrm{VS})$ \\
1798 & - \\
1812 & $1812(\mathrm{M}+)$ \\
1818 & $1817(\mathrm{M}+)$ \\
1822 & $1821(\mathrm{M})$ \\
1828 & $1828(\mathrm{VS})$ \\
1837 & $1837(\mathrm{M}+)$ \\
1839 & $1837(\mathrm{M}+)$ \\
1840 & - \\
1858 & $1857-1858(\mathrm{M}+)$ \\
1859 & $1857-1858(\mathrm{M}+)$ \\
1860 & $1860(\mathrm{M})$ \\
1865 & $1864(\mathrm{~S})$ \\
1880 & $1878(\mathrm{VS}) ; 1880(\mathrm{M})$ \\
1881 & $1880(\mathrm{M})$ \\
1888 & $1887-1888(\mathrm{M})$ \\
1899 & $1897(\mathrm{M}) ; 1899(\mathrm{~S})$ \\
1900 & $1899-1900(\mathrm{~S})$ \\
1915 & $1914-1915(\mathrm{M}+)$ \\
1916 & $1914-1915(\mathrm{M}+)$ \\
1920 & $1918-1919(\mathrm{M}+)$ \\
1926 & $1925-1926(\mathrm{VS})$ \\
1928 & $1926(\mathrm{VS})$ \\
1930 & $1930(\mathrm{M})$ \\
1941 & $1940-1941(\mathrm{~S})$ \\
1945 & $1943(\mathrm{M}+)$ \\
1947 & - \\
1965 & $1965(\mathrm{M}+)$ \\
1972 & $1972(\mathrm{~S})$ \\
1973 & $1972-1973(\mathrm{~S})$ \\
1978 & $1976(\mathrm{M})$ \\
1985 & $1983(\mathrm{VS})$ \\
1986 & $1986(\mathrm{M})$ \\
1987 & $1987(\mathrm{M})$ \\
1991 & $1990-1991(\mathrm{~S})$ \\
1999 & $1997-1998(\mathrm{~S})$ \\
2001 & - \\
\hline 69 & - \\
&
\end{tabular}

${ }^{\mathrm{a}} \mathrm{VS}$, very strong; $\mathrm{S}+$, stronger than $\mathrm{S} ; \mathrm{S}$, strong; $\mathrm{M}+$, stronger than $\mathrm{M}$; $\mathrm{M}$, moderate.

NCP region. The regional DWI of the NCP and the tree-ring cellulose $\delta^{18} \mathrm{O}$ chronology are compared in Figure $6 \mathrm{~b}$. The correlation coefficients between them are $r=-0.315$ $\left(p=2 \times 10^{-6}, n=217\right)$ for the interannual data. In addition, 10 year low-pass filter of the 2 series shows that the correlation on low frequency between our chronology and the DWI series also is significant $\left(r=-0.367, p=4 \times 10^{-8}, n=\right.$ 211). Although the correlations are very significant, the amplitudes of the two series in Figure $6 \mathrm{~b}$ exhibit a large difference. We suggest that this result may be attributed to the simple definition of the DWI because the DWI defines only five values (grades) to determine dry or wet conditions, and this simplicity limits evaluation of the actual amplitude of hydroclimate variability.

\subsection{Link With ENSO}

[30] The power spectrum analysis detects several significant periodicities on the tree-ring cellulose $\delta^{18} \mathrm{O}$ series. They are $4.17,5.03,5.21,6.64$, and 6.95 year periodicities, which are very similar to cycle of ENSO [Hocke, 2009; Gergis and Fowler, 2009]. Since ENSO is the most important factor influencing climate variability in most part of the earth [Allan et al., 1996], we will investigate the effect of ENSO on the NCP in this section.

[31] Spatial correlation analysis shows a significant negative and positive correlation between the actual precipitation at the Yuanping meteorological station and the tree-ring cellulose $\delta^{18} \mathrm{O}$ chronology and the SST in the eastern equatorial Pacific during 1954-2003 and 1854-2003 (see Figure 7), suggesting that there is a tight connection between hydroclimate variability of the NCP and ENSO (i.e., precipitation amount increases on the NCP with decreasing SST in the eastern equatorial Pacific, and vice versa). Using instrumental records, a possible mechanism was proposed for the negative correlation of the precipitation in NC with SST in the eastern equatorial Pacific by $W u$ [2002], Wu and Wang [2002], and Wu et al. [2003]. They indicated that the key to the correlation of the NCP summer precipitation with ENSO is a barotropic cyclone over northeast Asia. This anomalous cyclone comprises two tropical heat sources: one is over South Asia and the other is over the western North Pacific. The influences from the western North Pacific and South Asia are more obvious at the lower and upper troposphere, respectively. Anomalous western North Pacific heating induced by ENSO causes a meridional teleconnection pattern [Wu et al., 2003], and anomalous South Asian heating related to ENSO contributes to a zonal wave pattern over midlatitude Asia [Wu, 2002]. As a result, the cyclone over northeast Asia displaces southwestward in the ENSO-developing year, and anomalous northerly on the west flank of the cyclone reduces moisture supply into the NCP, leading to below normal rainfall on the NCP.

[32] We investigated the ENSO-hydroclimate relationship based on individual episodes of extremely dry and wet years

Table 3. Extremely Wet Years Detected by the Tree-Ring Cellulose $\delta^{18} \mathrm{O}$ Chronology With Classified La Niña Events From Gergis and Fowler [2009]

\begin{tabular}{cc}
\hline Extremely Wet Years & La Niña Events (Classify) \\
\hline 1786 & $1785(\mathrm{~W}) ; 1786(\mathrm{~S})$ \\
1790 & $1785(\mathrm{VS}) ; 1789(\mathrm{~W}) ; 1790(\mathrm{~S})$ \\
1795 & $1797(\mathrm{M}) ; 1798(\mathrm{~W})$ \\
1799 & $1801-1802(\mathrm{VS})$ \\
1802 & $1805(\mathrm{VS})$ \\
1807 & - \\
1816 & $1823(\mathrm{M})$ \\
1823 & $1823(\mathrm{M})$ \\
1824 & $1851(\mathrm{M})$ \\
1853 & - \\
1856 & $1868(\mathrm{~S}) ; 1870(\mathrm{VS})$ \\
1870 & $1870-1871(\mathrm{VS})$ \\
1871 & $1872(\mathrm{M}) ; 1873(\mathrm{VS})$ \\
1873 & $1878(\mathrm{~W}) ; 1879(\mathrm{E})$ \\
1879 & $1890(\mathrm{~S})$ \\
1890 & $1891(\mathrm{~W}) ; 1892(\mathrm{~S}) ; 1893(\mathrm{VS})$ \\
1893 & $1921(\mathrm{~W}) ; 1922(\mathrm{~S})$ \\
1922 & $1921(\mathrm{~W}) ; 1922(\mathrm{~S}) ; 1923(\mathrm{~W})$ \\
1923 & $1922(\mathrm{~S}) ; 1923(\mathrm{~W})$ \\
1924 & $1934(\mathrm{~W})$ \\
1935 & - \\
1939 & $1945(\mathrm{~W}) ; 1946(\mathrm{~S})$ \\
1946 & $1953(\mathrm{E})$ \\
1954 & $(\mathrm{~S}) ; 1996(\mathrm{M})$ \\
1996 & 1995 \\
\hline
\end{tabular}

${ }^{\mathrm{a}} \mathrm{E}$, extreme; VS, very strong; $\mathrm{S}$, strong; $\mathrm{M}$, moderate; $\mathrm{W}$, weak. 
on the NCP and El Niño and La Niña events. An extremely dry or wet year is defined as a year in which the cellulose $\delta^{18} \mathrm{O}$ value becomes higher or lower than average by $\pm 1 \sigma$ (1.79\%o) because of the significant negative correlation between the cellulose $\delta^{18} \mathrm{O}$ and precipitation, relative humidity and the PDSI (Figure 3). From 1784 to 2003, 35 and 22 years were detected as extremely dry and wet years in the tree-ring cellulose $\delta^{18} \mathrm{O}$ chronology (Tables 2 and 3 ), respectively.

[33] Although long-term SST records for the eastern equatorial Pacific are not available for the last several centuries, some El Niño and La Niña events have been identified in the historical documents, corals, tree rings and/or instrumental observations complied by Quinn and Neal [1992], Gergis and Fowler [2009], and NOAA (http://www.cpc. ncep.noaa.gov/products/analysis_monitoring/ensostuff/ ensoyears.shtml). In Table 2, we can see that most of the extremely dry years of the NCP follow El Niño events occurring in the previous or current year. Some very strong El Niño events seem to influence the summer hydroclimate of the NCP for the preceding 2 years, probably because a typical ENSO event tends to last for 18-24 months [Gergis and Fowler, 2009]. There is a similar connection between extremely wet years of the NCP and La Niña events, as shown in Table 3 . This correlation suggests that both El Niño and La Niña events strongly influence the hydroclimate conditions of the NCP throughout the period of 1784-2003.

\section{Conclusions}

[34] We developed a 220 year tree-ring cellulose $\delta^{18} \mathrm{O}$ chronology based on four Larix principis-rupprechtii trees growing on Luya Mountain of the NCP. The chronology shows significant negative correlations with local precipitation, relative humidity and the PDSI. It represents largescale, regional hydroclimate variations on the NCP that are revealed by spatial correlation analysis with a CRU TS3 precipitation data sets. These findings demonstrate that the chronology is an appropriate record of the hydroclimate variability of the NCP. The wetter periods were 1784-1834 and 1925 to the 1970 s, whereas the long-term drier mainly occurred during period of the 1970s-2000s. The highfrequency signals in the chronology can detect some drought or flood events that are highly consistent with the historical records. The low-frequency signals of the chronology show coherent variability with the decadal frequency of drought events and the area-weighted regional DWI ( $r=$ -0.367 ) in all of the NCP during 1784-2003. In addition, spatial correlation analysis suggests that there is a significant link between the hydroclimate of the NCP and ENSO. In most cases, extremely dry and wet years recorded in the chronology correspond to historical El Niño and La Niña events. This conclusion enhances our understanding of the relationship between the NCP hydroclimate and ENSO before the era of meteorological observations. However, more studies are necessary to document and understand the complexity of the NCP hydroclimate-ENSO relationship to forecast future climate change in the semiarid NCP.

[35] Acknowledgments. We thank Yinke Yang and Lei Wang for their help in our sample collection. We are grateful to Caiming Shen,
Renguang $\mathrm{Wu}$, and Masaki Sano for providing data or helpful discussion. We also would like to thank the editor and four anonymous reviewers, whose comments and suggestions were very helpful in improving the quality of the manuscript. This study was financially supported by a grant-inaid (Basic Research B: 19310002) by the Japan Society for the Promotion of Sciences, by the National Natural Science Foundation of China (40890051), and by the Hundred Talents Program of the Chinese Academy of Sciences.

\section{References}

Allan, R., J. Lindesay, and D. Parker (1996), El Nino-Southern Oscillation and Climatic Variability, Commonwealth Sci. and Indust. Res. Organ., Melbourne, Vic., Australia.

Cai, Q. F., Y. Liu, H. M. Song, and J. Y. Sun (2008), Tree-ring-based reconstruction of the April to September mean temperature since 1826 AD for north-central Shaanxi Province, China, Earth Sci., 51, 1099-1106.

Chen, H. (2007), Shanxi's catastrophic drought in third year of Guangxu of Qing Dynasty and this year's water resources situation [in Chinese with English abstract], Shanxi Hydrol., 164, 73-75.

Chinese National Meteorological Administration (1981), Yearly Charts of Dryness/Wetness in China for the Last 500-Year Period, Chin. Cartogr., Beijing.

Cook, E. R., K. J. Anchukaitis, B. M. Buckley, R. D. D’Arrigo, G. C. Jacoby, and W. E. Wright (2010), Asian monsoon failure and megadrought during the last millennium, Science, 328, 486-489, doi:10.1126/science. 1185188.

Coplen, T. B. (1996), New guidelines for reporting stable hydrogen, carbon, and oxygen isotope-ratio data, Geochim. Cosmochim. Acta, 60, 3359-3360, doi:10.1016/0016-7037(96)00263-3.

Craig, H., and L. I. Gordon (1965), Deuterium and Oxygen 18 Variations in the Ocean and the Marine Atmosphere, Cons. Naz. delle Ric. Lab. de Geol. Nucl., Spoleto, Italy.

Cullen, L., and P. F. Grierson (2009), Multi-decadal scale variability in autumn-winter rainfall in south-western Australia since 1655 BP as reconstructed from tree rings of Callitris columellaris, Clim. Dyn., 33, 433-444, doi:10.1007/s00382-008-0457-8.

Dai, A., K. E. Trenberth, and T. Qian (2004), A global dataset of Palmer Drought Severity Index for 1870-2002: Relationship with soil moisture and effects of surface warming, J. Hydrometeorol., 5, 1117-1130, doi:10.1175/JHM-386.1.

Ding, Y. (1994), Monsoons Over China, Kluwer Acad., Dordrecht, Netherlands.

Dongmann, G., H. Nurnberg, H. Forstel, and K. Wagener (1974), On the enrichment of $\mathrm{H}_{2}{ }^{18} \mathrm{O}$ in the leaves of transpiring plants, Radiat. Environ. Biophys., 11, 41-52, doi:10.1007/BF01323099.

Fang, K., X. Gou, F. Chen, J. Li, R. D’Arrigo, E. Cook, T. Yang, and N. Davi (2009), Reconstructed droughts for the southeastern Tibetan Plateau over the past 568 years and its linkages to the Pacific and Atlantic Ocean climate variability, Clim. Dyn., 35, 577-585.

Farquhar, G. D., and L. A. Cernusak (2005), On the isotopic composition of leaf water in the non-steady state, Funct. Plant Biol., 32, 293-303, doi:10.1071/FP04232.

Feng, S., and Q. Hu (2004), Variations in the teleconnection of ENSO and summer rainfall in northern China: A role of the Indian summer monsoon, J. Clim., 17, 4871-4881, doi:10.1175/JCLI-3245.1.

Fritts, H. C. (1976), Tree Rings and Climate, 567 pp., Academic, London. $\mathrm{Fu}, \mathrm{C}$, and Q. Wang (1992), The definition and detection of the abrupt climatic change [in Chinese with English abstract], Chin. J. Atmos. Sci., 16, 482-493.

Fu, G., S. P. Charles, J. Yu, and C. Liu (2009), Decadal climatic variability, trends, and future scenarios for the North China Plain, J. Clim., 22, 2111-2123, doi:10.1175/2008JCLI2605.1.

Ge, Q. S., J. H. Dai, F. N. He, Y. Pan, and M. M. Wang (2008), Land use changes and their relations with carbon cycles over the past 300a in China, Earth Sci., 51, 871-884.

Gergis, J. L., and A. M. Fowler (2009), A history of ENSO events since AD 1525: Implications for future climate change, Clim. Change, 92, 343-387, doi:10.1007/s10584-008-9476-z.

Gong, D., and S. Wang (1999), Impacts of ENSO on rainfall of global land and China, Chin. Sci. Bull., 44, 852-857, doi:10.1007/BF02885036.

Gou, X., F. Chen, E. Cook, G. Jacoby, M. Yang, and J. Li (2007), Streamflow variations of the Yellow River over the past 593 years in western China reconstructed from tree rings, Water Resour. Res., 43, W06434, doi:10.1029/2006WR005705.

Hocke, K. (2009), QBO in solar wind speed and its relation to ENSO, J. Atmos. Sol. Terr. Phys., 71, 216-220, doi:10.1016/j.jastp.2008.11.017.

Holmes, R. L. (1983), Computer-assisted quality control in tree-ring dating and measurement, Tree Ring Bull., 43(1), 69-78. 
Huang, R., and Y. Wu (1989), The influence of ENSO on the summer climate change in China and its mechanism, Adv. Atmos. Sci., 6, 21-32, doi:10.1007/BF02656915.

Leavitt, S. W. (2010), Tree-ring C-H-O isotope variability and sampling, Sci. Total Environ., 408, 5244-5253, doi:10.1016/j.scitotenv.2010.07.057.

Leavitt, S. W., and A. Long (1984), Sampling strategy for stable carbon isotope analysis of tree rings in pine, Nature, 311, 145-147, doi:10.1038/ $311145 \mathrm{a} 0$.

Leavitt, S. W., K. Treydte, and Y. Liu (2010), Environment in time and space: Opportunities from tree-ring isotope networks, in Isoscapes, pp. 113-135, Springer, Dordrecht, Netherlands.

Li, Q., Y. Liu, Q. F. Cai, J. Y. Sun, L. Yi, H. M. Song, and L. Wang (2006), Reconstruction of annual precipitation since 1686 A.D. from Ningwu region, Shanxi Province [in Chinese with English abstract], Quat. Sci., 26, 999-1006.

Li, Q., T. Nakatsuka, K. Kawamura, Y. Liu, and H. Song (2011a), Regional hydroclimate and precipitation $\delta^{18} \mathrm{O}$ revealed in tree-ring cellulose $\delta^{18} \mathrm{O}$ from different tree species in semi-arid northern China, Chem. Geol., 282, 19-28, doi:10.1016/j.chemgeo.2011.01.004

Li, Z. H., N. Labbe, S. G. Driese, and H. D. Grissino-Mayer (2011b), Micro-scale analysis of tree-ring $\delta^{18} \mathrm{O}$ and $\delta^{13} \mathrm{C}$ on $\alpha$-cellulose spline reveals high-resolution intra-annual climate variability and tropical cyclone activity, Chem. Geol., 284, 138-147, doi:10.1016/j.chemgeo. 2011.02.015.

Liang, E., X. Liu, Y. Yuan, N. Qin, X. Fang, L. Huang, H. Zhu, L. Wang, and $X$. Shao (2006), The 1920s drought recorded by tree rings and historical documents in the semi-arid and arid areas of northern China, Clim. Change, 79, 403-432, doi:10.1007/s10584-006-9082-x.

Liu, X., D. Qin, X. Shao, L. Zhao, T. Chen, and J. Ren (2003), Variation and abrupt change of precipitation in Nyingchi Prefecture of Tibet Autonomous Region in past 350 years, J. Glaciol. Geocryol., 25, 375-379.

Liu, Y., Q. Cai, J. Shi, M. K. Hughes, J. E. Kutzbach, Z. Liu, F. Ni, and Z. An (2005), Seasonal precipitation in the south-central Helan Mountain region, China, reconstructed from tree-ring width for the past 224 years, Can. J. For. Res., 35, 2403-2412, doi:10.1139/x05-168.

Liu, Y., H. W. Linderholm, H. Song, Q. Cai, Q. Tian, J. Sun, D. Chen, E. Simelton, K. Seftigen, and H. Tian (2009a), Temperature variations recorded in Pinus tabulaeformis tree rings from the southern and northern slopes of the central Qinling Mountains, central China, Boreas, 38, 285-291, doi:10.1111/j.1502-3885.2008.00065.x.

Liu, Y., G. Bao, H. Song, Q. Cai, and J. Sun (2009b), Precipitation reconstruction from Hailar pine (Pinus sylvestris var. mongolica) tree rings in the Hailar region, Inner Mongolia, China back to 1865 AD, Palaeogeogr. Palaeoclimatol. Palaeoecol., 282, 81-87, doi:10.1016/j.palaeo.2009.08.012.

Liu, Y., H. Tian, H. Song, and J. Liang (2010), Tree ring precipitation reconstruction in the Chifeng-Weichang region, China, and East Asian summer monsoon variation since AD 1777, J. Geophys. Res., 115 D06103, doi:10.1029/2009JD012330.

Loader, N., I. Robertson, A. Barker, V. Switsur, and J. Waterhouse (1997), An improved technique for the batch processing of small wholewood samples to $\alpha$-cellulose, Chem. Geol., 136, 313-317, doi:10.1016/ S0009-2541(96)00133-7.

Masson-Delmotte, V., G. Raffalli-Delerce, P. Danis, P. Yiou, M. Stievenard, F. Guibal, O. Mestre, V. Bernard, H. Goosse, and G. Hoffmann (2005), Changes in European precipitation seasonality and in drought frequencies revealed by a four-century-long tree-ring isotopic record from Brittany, western France, Clim. Dyn., 24, 57-69, doi:10.1007/s00382-004-0458-1.

McCarroll, D., and N. J. Loader (2004), Stable isotopes in tree rings, Quat. Sci. Rev., 23, 771-801, doi:10.1016/j.quascirev.2003.06.017.

McCarroll, D., and F. Pawellek (1998), Stable carbon isotope ratios of latewood cellulose in Pinus sylvestris from northern Finland: Variability and signal-strength, Holocene, 8, 675-684, doi:10.1191/095968398675987498.

Nakatsuka, T., K. Ohnishi, T. Hara, A. Sumida, D. Mitsuishi, N. Kurita and S. Uemura (2004), Oxygen and carbon isotopic ratios of tree-ring cellulose in a conifer-hardwood mixed forest in northern Japan, Geochem. J. Jpn., 38, 77-88.

Nakatsuka, T., K. Ohnishi, and T. Hara (2008), Reconstruction of summer temperature variation by hydrogen and oxygen isotopic ratios of larch tree-ring cellulose in Kamchatka Peninsula [in Japanese], Mon. Chikyu, 30, 207-215.

Palmer, W. C. (1965), Meteorological drought, Res. Pap. 45, U.S. Dept. of Commer. Weather Bur., Washington, D. C.

Piao, S., P. Ciais, Y. Huang, Z. Shen, S. Peng, J. Li, L. Zhou, H. Liu, Y. Ma, and Y. Ding (2010), The impacts of climate change on water resources and agriculture in China, Nature, 467, 43-51, doi:10.1038/nature09364.

Qian, W., and Y. Zhu (2001), Climate change in China from 1880 to 1998 and its impact on the environmental condition, Clim. Change, 50, 419-444, doi:10.1023/A:1010673212131.
Quinn, W. H., and V. T. Neal (1992), The historical record of El Nino events, in Climate Since AD 1500, pp. 623-648, Routledge, London.

Raffalli-Delerce, G., V. Masson-Delmotte, J. Dupouey, M. Stievenard N. Breda, and J. Moisselin (2004), Reconstruction of summer droughts using tree-ring cellulose isotopes: A calibration study with living oaks from Brittany (western France), Tellus, Ser. B, 56, 160-174, doi:10.1111/j.1600-0889.2004.00086.x.

Robertson, I., J. Rolfe, V. R. Switsur, A. H. C. Carter, M. A. Hall, A. C. Barker, and J. S. Waterhouse (1997), Signal strength and climate relationships in ${ }^{13} \mathrm{C} /{ }^{12} \mathrm{C}$ ratios of tree-ring cellulose from oak in southwest Finland, Geophys. Res. Lett., 24, 1487-1490, doi:10.1029/97GL01293.

Roden, J. S., G. Lin, and J. R. Ehleringer (2000), A mechanistic model for interpretation of hydrogen and oxygen isotope ratios in tree-ring cellulose, Geochim. Cosmochim. Acta, 64, 21-35, doi:10.1016/S0016-7037(99) 00195-7.

Sakai, Y., M. Takahashi, and N. Tanaka (2007), Root biomass and distribution of a Picea-Abies stand and a Larix-Betula stand in pumiceous Entisols in Japan, J. For. Res., 12, 120-125, doi:10.1007/s10310-006-0270-3.

Sano, M., B. M. Buckley, and T. Sweda (2009), Tree-ring based hydroclimate reconstruction over northern Vietnam from Fokienia hodginsii: Eighteenth century mega-drought and tropical Pacific influence, Clim. Dyn., 33, 331-340, doi:10.1007/s00382-008-0454-y.

Saurer, M., S. Borella, and M. Leuenberger (1997), $\delta^{18} \mathrm{O}$ of tree rings of beech (Fagus silvatica) as a record of $\delta^{18} \mathrm{O}$ of the growing season precipitation, Tellus, Ser. B, 49, 80-92, doi:10.1034/j.1600-0889.49.issue1.6.x. Saurer, M., P. Cherubini, C. Reynolds-Henne, K. Treydte, W. Anderson, and R. Siegwolf (2008), An investigation of the common signal in tree ring stable isotope chronologies at temperate sites, J. Geophys. Res., 113, G04035, doi:10.1029/2008JG000689.

Sharp, Z., V. Atudorei, and T. Durakiewicz (2001), A rapid method for determination of hydrogen and oxygen isotope ratios from water and hydrous minerals, Chem. Geol., 178, 197-210, doi:10.1016/S00092541(01)00262-5.

Shen, C., W. C. Wang, Z. Hao, and W. Gong (2007), Exceptional drought events over eastern China during the last five centuries, Clim. Change, 85, 453-471, doi:10.1007/s10584-007-9283-y.

Shen, C., W. C. Wang, Z. Hao, and W. Gong (2008), Characteristics of anomalous precipitation events over eastern China during the past five centuries, Clim. Dyn., 31, 463-476, doi:10.1007/s00382-007-0323-0.

State Office of State Flood Control and Drought Relief Headquarters (2007), Flood and Drought Disasters in China [in Chinese], China Water Power, Beijing.

Stokes, M. A., and T. L. Smiley (1996), An Introduction to Tree-Ring Dating, Univ. of Arizona Press, Tucson.

Takata, K., K. Saito, and T. Yasunari (2009), Changes in the Asian monsoon climate during 1700-1850 induced by pre-industrial cultivation, Proc. Natl. Acad. Sci. U. S. A., 106, 9586-9589, doi:10.1073/pnas.0807346106.

Tene, A., B. Tobin, J. Dyckmans, D. Ray, K. Black, and M. Nieuwenhuis (2011), Assessment of tree response to drought: Validation of a methodology to identify and test proxies for monitoring past environmental changes in trees, Tree Physiol., 31, 309-322, doi:10.1093/treephys/tpq114.

Tilahun, K. (2006), Analysis of rainfall climate and evapo-transpiration in arid and semi-arid regions of Ethiopia using data over the last half a century, J. Arid Environ., 64, 474-487, doi:10.1016/j.jaridenv.2005.06.013.

Treydte, K. S., G. H. Schleser, G. Helle, D. C. Frank, M. Winiger, G. H. Haug, and J. Esper (2006), The twentieth century was the wettest period in northern Pakistan over the past millennium, Nature, 440, 1179-1182, doi:10.1038/nature04743.

Wang, Q., N. Qin, Z. Zhang, H. Tang, F. Chen, and R. Qi (2007), Precipitation change and its impact on eco-environment of Qinghai Plateau for the last 40 years, J. Desert Res., 27, 153-158.

Wigley, T., K. Briffa, and P. Jones (1984), Average value of correlated time series, with applications in dendroclimatology and hydrometeorology, J. Appl. Meteorol., 23, 201-213, doi:10.1175/1520-0450(1984) $023<0201$ :OTAVOC $>2.0 . \mathrm{CO} ; 2$.

Wu, R. (2002), A mid-latitude Asian circulation anomaly pattern in boreal summer and its connection with the Indian and East Asian summer monsoons, Int. J. Climatol., 22, 1879-1895, doi:10.1002/joc.845.

Wu, R., and B. Wang (2002), A contrast of the East Asian summer monsoonENSO relationship between $1962-77$ and 1978-93, J. Clim., 15, 3266-3279, doi:10.1175/1520-0442(2002)015<3266:ACOTEA $>2.0$. CO $; 2$

Wu, R., Z. Hu, and B. Kirtman (2003), Evolution of ENSO-related rainfall anomalies in East Asia, J. Clim., 16, 3742-3758, doi:10.1175/15200442(2003)016<3742:EOERAI $>2.0$. CO;2.

Yi, L., Y. Liu, H. Song, Q. Li, Q. Cai, Y. Yang, and J. Sun (2006), Summer temperature variations since 1676 AD in Luya Mountain, Shanxi Province of China, inferred from tree rings [in Chinese with English abstract], J. Glaciol. Geocryol., 28, 330-336. 
Zeng, Z., X. Fang, Y. Ye, X. Zhang, and L. Xiao (2009), Comparison of disaster situation and causes of three extreme droughts in China over the past 300 years [in Chinese with English abstract], J. Catastrophology, 24, 116-122.

Zhang, D. (1988a), The method for reconstruction of the dryness/wetness series in China for the last 500 years and its reliability, in The Reconstruction of Climate in China for Historical Times, edited by J. Zhang, pp. 18-31, Science, Beijing.

Zhang, D., X. Li, and Y. Liang (2003), Supplement of yearly charts of dryness/wetness in China for the last 500-year period, 1993-2000, J. Appl. Meteorol. Sci., 14, 379-389.

Zhang, J. (1988b), Chronology Table of Natural Disasters in Shanxi Province, China, Shanxi Chorography Off., Taiyuan, China.

Zhang, R., A. Sumi, and M. Kimoto (1999), A diagnostic study of the impact of El Nino on the precipitation in China, Adv. Atmos. Sci., 16, 229-241, doi:10.1007/BF02973084.
Zhang, Y. (2003), River characteristics and hydrologic analysis of Sanggan River [in Chinese with English abstract], Shanxi Hydrotechnics, 147, 36-38.

Zhou, T., R. Yu, J. Zhang, H. Drange, C. Cassou, C. Deser, D. L. R. Hodson, E. Sanchez-Gomez, J. Li, and N. Keenlyside (2009), Why the western Pacific subtropical high has extended westward since the late 1970s, J. Clim., 22, 2199-2215, doi:10.1175/2008JCLI2527.1.

K. Kawamura, Institute of Low Temperature Science, Hokkaido University, Sapporo 060-0819, Japan.

Q. Li, Y. Liu, and H. Song, State Key Laboratory of Loess and Quaternary Geology, Institute of Earth Environment, Chinese Academy of Sciences, Xi'an 710075, China. (liqiang@ieecas.cn)

T. Nakatsuka, Graduate School of Environmental Studies, Nagoya University, Nagoya 464-8601, Japan. 